\title{
Breaking Down Silos by Sharing Innovation in Academic Family Medicine
}

\author{
Cristy Page, MD, MPH; Philip D. Sloane, MD, MPH
}

(Fam Med. 2020;52(6):414-6.)

doi: 10.22454/FamMed.2020.969649

$\mathrm{n}$ the early years of our specialty, considerable debate centered around whether fam-

ily medicine teaching practices should be affiliated with major academic medical institutions. ${ }^{1,2}$ Since then, departments with robust clinical operations embedded within the academic health center have become essential to our ability to provide innovation within health care and to influence the course of medical education and practice.

This integration of family medicine teaching practices with academic health centers has progressed markedly over the past quarter century, fostered in large measure by evolution of the health centers themselves. Key trends fostering this integration included (1) marketplace dynamics, forcing academic health centers to compete more aggressively, (2) the increasing need for chronic disease management and geriatric care, (3) a massive transfer of care from the hospital to office and outpatient settings, and (4) an increasing appreciation that care of medically indigent and vulnerable populations is part of the mission of most academic health centers. ${ }^{3}$ An additional factor-albeit often not openly acknowledged by academic health center leadership-is that family medicine practices are revenue generators for the health system, accruing six to seven times as many charges outside the department as within. ${ }^{4,5}$

In recent decades, departments of family medicine have expanded their clinical activities far beyond the original focus as training sites for students and residents. Early steps included hiring faculty to primarily see patients, expanding the clinic's outreach to include community service, and developing formal ties with community practices. ${ }^{6}$ In 2004 , the Future of Family Medicine Task Force provided added impetus for these changes by calling for a new practice model with open-access scheduling, chronic disease management systems, group visits to blend medical care and health education, and electronic health records and encouraging its implementation and testing within academic family medicine programs. ${ }^{7}$

The pace and degree of diversification of family medicine center practices has been even more rapid and diverse in this decade, accompanied by ever greater interdependency with the academic health center. Elements of these changes have included major roles in the development of care networks, as academic health centers evolved to lead large health systems, provide leadership in care of underserved populations, practice population health, and implement quality standards. ${ }^{3}$ In our own academic practice, as an example, we have in recent years redesigned and renovated our family medicine center to be better suited for team care. We have programmed and reprogrammed our electronic health record to help health professionals navigate the transition to and multiple options that are part of the EPIC electronic health record. We have developed and implemented systems to track and improve metrics such as colon cancer screening. We have created de novo a system to improve hospital-to-community transitional care and have determined the equipment and staffing needs for a new urgent care offering by our practice. And we are not alone. Others have diversified in such varied ways as providing

From the Department of Family Medicine (Drs Sloane and Page), the Office of the Dean, School of Medicine (Dr Page), and the Cecil G. Sheps Center for Health Services Research (Dr Sloane), University of North Carolina at Chapel Hill. 
cosmetic services, ${ }^{8}$ assisting in coordination of primary care within health care networks, ${ }^{9}$ and converting a family medicine teaching practice into a federally qualified community health center. ${ }^{10}$

Unfortunately, these innovations are almost always created practically de novo by each practice, often at tremendous effort and through much trial and error, even though other departments are often doing similar things. This was demonstrated to us 15 years ago when, at a sparsely-attended session during the American Academy of Family Physicians annual meeting, a presenter described how his organization had expended innumerable physician and technical staff hours developing an electronic system for tracking diabetics. What they described was identical to an effort that our medical practice was doing at the same time. "There are probably at least 1,500 practices and organizations doing this same thing," we muttered, marveling at the effort and energy that could be spared by more coordination and better dissemination of methods.

Why so much duplication of effort? Why is reinvention of the wheel a hallmark of American medicine? The reason, of course, is that we work in siloed systems without effective coordination, the legacy of America's frontier mentality that, as Larry Green wrote, "was supportive of lone individuals, doing largely as they pleased within fragmented systems." 11 This tradition is, however, increasingly counterproductive, and is one of the main reasons why nearly one-third of overall health care costs go to coordinating and administering within and between these entities.

We acknowledge that context plays a considerable role in what programs are suitable for each entity. Implementation and design will, and should, vary significantly based on context, institutional culture, patient panels, and scale, among other differentiators. We do not intend to suggest a one-size-fits-all solution for every clinical challenge. Rather, we hope to provide examples that may guide others in developing sustainable models and foreseeing potential challenges when implementing their own innovations.

As primary care professionals, we live in this fragmented, rapidly changing environment and try to make the best of it. When we begin new initiatives, we are aware that others have probably done something similar, if not identical. However, when we turn to the academic literature, we find a striking lack of information on the nuts and bolts of conducting and improving primary care practice. Instead, the majority of our literature focuses on diagnosis and treatment. In the rare instance when a practice innovation is presented, the "how to" is typically relegated to a paragraph or two under "Methods," with the vast majority of text and virtually all of the tables and figures devoted to convincing the reader and reviewer that the innovation was statistically successful.

Family Medicine's recent call for papers, entitled "Innovative Efforts Toward High Performing Academic Family Medicine Practices," was an attempt to fill this void in the literature and create a shared conversation in our siloed system. In contrast with typical academic articles on innovations, the call for papers asked for much more detail on the innovation, ideally with enough detail to be useful to others who may be interested in introducing a similar innovation. This issue of Family Medicine includes six papers submitted in response to that call for papers. We hope these serve as a guide for others in their quest for quality improvement and in their transition to a high-performing, innovative academic practice- providing accessible, high quality, value based care; practicing whole-person, holistic medicine; and focusing on provider, learner, and staff well-being. As such, we curated the articles for this issue to exemplify the innovative practice improvements we see as characteristic of the family medicine practice of the future.

Access is among the most frequently discussed essentials for a high-functioning primary care practice. With patients seeking on-demand care and ever greater flexibility, Amir Barzin, DO, MS, and colleagues offer guidance on providing convenience while improving access and increasing preventive screening. The authors demonstrate how practices can develop an urgent care service line that yields a decrease in emergency department visits while supporting the existing practice with an increase in both patients establishing care and continuity care during the same period. ${ }^{12}$ Similarly, Tommy Koonce, MD, MPH and Dana Neutze, MD, PhD, discuss in detail the redesign of an academic family medicine practice, demonstrating that it can be done without compromising patient care during renovation, and the ultimate result is increased access while bolstering quality of care.$^{13} \mathrm{~A}$ third paper addresses both value and economic impact by presenting the effect of a minor procedure service on the cost of care for a health plan, modeling the potential 
for considerably decreased cost of care by providing minor procedures in the primary care setting. ${ }^{14}$ Rather than referring patients to costlier specialists, family physicians utilize their full-scope training to perform skin, musculoskeletal, and reproductive procedures, yielding a $70 \%$ cost savings for patients and a $\$ 2.33$ return on every dollar spent to implement and maintain the service, not to mention the increase in convenience for patients. ${ }^{14}$

Key to future primary care practice is a holistic approach, treating not just illness but advancing whole-person health. In "Building a Viable Weight Management Program in a Patient-Centered Medical Home," Dr WilhoitReeves and colleagues describe the implementation of an intensive behavioral therapy program in an academic medical center. The authors explain how, through creative and careful attention to cost and reimbursement, they have served nearly 700 patients, with impressive results and a sustainable financial model. Key to their approach is an interprofessional team comprised of clinicians, social workers, and dietitians using a mix of nutrition guidelines and cognitive behavioral therapy techniques. ${ }^{15}$

Our final two articles in this issue address the important topic of training residents in new, innovative practice models and approaches. Emphasizing the importance of our learners, Dr Hofkamp et al describe the potential of curricular changes in ambulatory settings to improve resident engagement and foster their well-being, demonstrating improvement in resident self-perception of personal wellness and preparedness reflected in postimplementation survey results. ${ }^{16}$ The final paper addresses the need for today's family physicians to possess practice management acumen, positing that an understanding of financial issues and quality improvement is key to innovative and sustainable practice. The article demonstrates that practice management residency curricula can lead to an increase in resident ability to subsequently implement processes that will improve patient care. Learners also demonstrate a better understanding of productivity and financial elements of practice management. ${ }^{17}$

Of course, there are innumerable ways to innovate and improve performance in an academic medicine practice. While these selections do not represent the entire range of potential practice and quality improvements available, we hope they will facilitate the adoption of similar care models and serve as a valuable addition to the existing literature. Most importantly, we hope this issue will encourage our discipline to reflect on how we can better communicate and disseminate innovations, so that we can move forward more briskly and efficiently as a discipline, breaking down silos and working together toward the benefit of our discipline, the health systems in which we work, and our society.

CORRESPONDING AUTHOR: Address correspondence to Dr Philip D. Sloane, Department of Family Medicine, University of North Carolina at Chapel Hill, Aycock Family Medicine Building, Chapel Hill, NC 27599-7595. 919-9663711.psloane@med.unc.edu.

\section{References}

1. Geyman JP. Family practice in evolution: progress, problems and projections. N Engl J Med. 1978;298(11):593-601.

2. Sadovsky R, Plotz CM. The pros and cons of the family practice center located in the academic medical institution. J Med Educ. 1979;54(11):895-897.

3. Newton WP, DuBard CA. Shaping the future of academic health centers: the potential contributions of departments of family medicine. Ann Fam Med. 2006;4(suppl 1):S2-S11.

4. Howell RE. What is a family practice center worth? J Fam Pract. 1991;32(6):563-564.

5. Schneeweiss R, Ellsbury K, Hart LG, Geyman JP. The economic impact and multiplier effect of a family practice clinic on an academic medical center. JAMA. 1989;262(3):370-375.

6. The Association of Departments of Family Medicine Task Force on Clinical Practice in US family medicine departments in academic medical centers. Clinical practice in academic medical center departments of family medicine. Fam Med. 1997;29(1):15-20.

7. Michener L. New models of care in family medicine. Ann Fam Med. 2004;2(6):613.

8. Paladine HL, White B, Miller K, Feifer C. Cosmetic services in the family health center: a roadmap. Fam Med. 2011;43(2):121-122.

9. Ogle KD, Boulé R, Boyd RJ, et al. Family medicine in 2018 . Can Fam Physician. 2010;56(4):313-315, 316-319.

10. Cousineau MR, Flores H, Cheng S, et al. Transforming a family medicine center and residency program into a federally qualified health center. Acad Med. 2013;88(5):657-662.

11. Green LA. The view from 2020: how family practice failed. Fam Med. 2001;33(4):320-324.

12. Barzin A, Seybold O, Page C. Integrating an urgent care clinic into an academic family medicine practice. Fam Med 2020;52(6):440-443.

13. Koonce T, Neutze D. Improving patient care through workspace renovation and redesign: a lean approach. Fam Med. 2020;52(6):435-439.

14. Nelligan I, Montacute T, Browne MA, Lin S. Impact of a family medicine minor procedure service on cost of care for a health plan. Fam Med. 2020;52(6):440-443.

15. Wilhoit-Reeves S, Sisler L, Aymes S, Ortiz-Pujols S, Porterfield $\mathrm{D}$, Goldstein A. Building a viable weight management program in a patient-centered medical home. Fam Med. 2020;52(6):427-431.

16. Hofkamp H, Cheng A, Ramalingam N, Rdesinski, R, Garvin R. Effects of clinic first educational interventions on resident wellness and engagement. Fam Med. 2020;52(6):422-426.

17. Malaty J, Williams M, Carek P. Impact of providing data on family medicine practice management education. Fam Med. 2020;52(6):432-434. 